Fournal of Medical Genetics (1976). 13, 434-438.

\title{
Infantile cystinosis in France: genetics, incidence, geographic distribution*
}

\author{
E. BOIS, J. FEINGOLD, P. FRENAY, and M.-L. BRIARD \\ Laboratoire de Génétique Epidémiologique, Inserm, Chateau de Longchamp, Paris 16; Unité de Recherches sur les Maladies \\ du Métabolisme chez l'Enfant, INSERM; Unité de Recherches de Génétique Médicale, INSERM; and Institut \\ Géographique National, Paris, France
}

Summary. A national distribution of 66 French patients, from 49 sibships, has been studied. Segregation analysis, using the maximum likelihood method, was found to agree with the theoretical values expected in recessive autosomal inheritance. The birthplaces of these patients show an unequal geographic distribution of cystinosis, the incidence being higher in Western France. Compared with the total number of live births during the period 1959 to 1972, the minimum incidence of the condition in the province of Brittany is 1 per 25909 , and the gene frequency 0.0062. In the rest of France, the minimum incidence is 1 per 326,440 and the gene frequency 0.0018 . Application of Dahlberg's formula gives a similar result. The mean inbreeding coefficient is $530 \times 10^{-5}$, a figure 23 times higher than the mean coefficient of France. An indirect test of inbreeding, the distance between parental birthplaces, was studied, first using the French administrative boundaries, second by using kilometres. This distance was constantly smaller for the parents of patients than for the parents of controls. Analysis of two erythrocyte polymorphisms (ABO and $\mathrm{Rh}$ ) showed a large excess of group A patients when compared with overall French data. These findings are difficult to interpret on genetic grounds. The genetic reasons for the unequal geographic distribution of cystinosis in France are discussed.

Infantile nephropathic cystinosis is a metabolic hereditary disorder involving the kidneys and producing renal tubular abnormalities of the Fanconi syndrome, with rickets and growth retardation (Abderhalden, 1903; Bickel and Harris, 1952; Lamy et al, 1968; Schulman, 1974). The diagnosis, suggested by the clinical picture, is easily established by the visualization of L-cystine crystals in the eyes, as seen by slit-lamp examination, or in bone marrow and lymph nodes. The mean free-cystine content of leucocytes from patients is 80 times normal (Schneider, 1969; Kroll et al, 1973). Clinical onset usually occurs around 6 months of age. The course of the disease is progressive and most patients die within 10 years of chronic renal failure, unless

\footnotetext{
Received 9 October 1975.

* This work was supported by grants from the 'Institut National de la Santé et de la Recherche Médicale' (A.T.P. 29).
}

haemodialysis and renal transplantation are performed (Schulman, 1973).

There are two other variants of cystinosis, less serious and less extensively studied. In adults, cystinosis is seen in a completely benign form. An intermediate or late-onset type is an attenuated form appearing in late childhood or early adult life (Brubaker et al, 1970; Goldman et al, 1971; Kroll and Lichte, 1973).

Despite the paucity of genetic studies, pedigree studies have shown that the condition is inherited as an autosomal recessive trait in all variants. There $N$ has been confirmation by biochemical methods for $N$ identifying heterozygote status (Schulman, 1970). Early prenatal diagnosis is possible (Milunsky $e t$ al, 1970).

Classic childhood cystinosis-the form presented by patients in this study-is very uncommon. 434 
Before 1964, 113 cases had been recorded (Paulin, 1964). The exact incidence of the condition in the general population is not known. The sole estimate is that of Bickel and Harris (1952) in the Wolverhampton, Coventry, and Birmingham areas (Great Britain), and is 1 in 40000 . Cystinosis has probably never been confirmed in Finland, where a general detection programme of genetic diseases was established some years ago (Norio et al, 1973). Several families with affected children are mentioned in the province of Quebec (Canada), in the region of Saint-Jean Lake, where an unusual cluster of hereditary tyrosinaemia has been described, the population ancestry coming from the French provinces of Brittany and Normandy ( $P$. Bergeron, 1974, personal communication). The incidence of cystinosis is very low in British Columbia (J. R. Miller, 1974, personal communication). Williamson (1952) reported 23 cases, 8 of Swiss origin with high inbreeding. In Israël, a number of genetic diseases was seen to occur with unusually high frequency in the North African Jewish community, particularly cystinosis: $75 \%$ of the patients with this condition in the whole of Israël were North Africans (Moses et al, 1973; Moses, 1975).

The main purpose of this study was to determine the incidence of cystinosis in France and the genetic structure of the French population as regards this condition.

\section{Subjects and methods}

Questionnaires were sent to the 176 departments of paediatrics of the French hospitals. The total response rate was $79.5 \%$, with $92.1 \%$ for the University hospitals outside of Paris and $82.4 \%$ for those in Paris and surroundings. Because of the severity of the disease, the probability of patients with cystinosis registering at University hospitals is greater. The distribution of the responses is relatively homogeneous throughout the whole of France. The investigation was also extended to the various haemodialysis centres. This allowed us to verify and supplement the data. In some cases a particular questionnaire was sent to the parents of living patients.

The denominator of the cystinosis incidence rate for France was the number of live births during the study, using the national and regional data of the French Vital Statistics INSEE (Institut National de la Statistique et des Etudes Economiques).

The cases of cystinosis were then distributed into regions determined by the birthplaces of the patients. The birthplaces of parents of patients and of the control sample (defined as children born in the same place as the patients, immediately before and immediately after them) were obtained from the local administration. The distance between the birthplaces of parents was studied, first using the French administrative boundaries and second using kilometres by curvimetric technique on a 1/200 000 map.
TABLE I

DISTRIBUTION OF 49 SIBSHIPS ACCORDING TO SIZE OF SIBSHIP AND TO NUMBER OF AFFECTED CHILDREN

\begin{tabular}{|c|c|c|c|c|c|c|c|c|c|}
\hline $\begin{array}{cr}\text { No. } & \begin{array}{l}\text { Size of } \\
\text { sibship }\end{array} \\
\text { Affected } & \end{array}$ & 1 & 2 & 3 & 4 & 5 & 9 & 11 & 12 & Total \\
\hline $\begin{array}{l}1 \text { affected } \\
2 \text { affected } \\
4 \text { affected }\end{array}$ & -7 & $\begin{array}{r}10 \\
4 \\
-\end{array}$ & $\begin{array}{r}7 \\
3 \\
\end{array}$ & $\begin{array}{l}4 \\
6 \\
\end{array}$ & $\frac{4}{1}$ & $\underline{-}$ & $\overline{1}$ & $\underline{1}$ & $\begin{array}{r}34 \\
14 \\
1 \\
\end{array}$ \\
\hline Total of sibships & 7 & 14 & 10 & 10 & 5 & 1 & 1 & 1 & 49 \\
\hline
\end{tabular}

\section{Results and discussion}

Using clinical, evolutive, and biochemical criteria, 66 patients with infantile nephropathic cystinosis were found. These cases occurred in 49 sibships totalling 162 children. Table I summarizes the size of sibships and the number of sibships with one or more affected individuals.

Among the 42 sibships with more than 1 child, 15, a proportion of $35.7 \%$, included 2 or more patients. In a study on 102 sibships, Paulin (1964) established this ratio as $25.5 \%$. This ratio, however, varies with the fecundity of the parents.

There were 36 male and 30 female patients. The index of masculinity, 0.55 , does not differ from the index of the general population at the same age.

Segregation analysis was performed assuming complete ascertainment and full penetrance. The proportion of affected children was estimated using the maximum likelihood method. For the $42 \mathrm{sib}-$ ships used in segregation analysis, this proportion is 0.236 , the standard deviation being 0.031 , which is in good agreement with the theoretical value expected in recessive autosomal inheritance.

\section{Geographic distribution-incidence}

With the exception of 2 patients born outside France, the birthplaces of all patients are recorded in Fig. 1. This figure shows clearly the extremely unequal distribution of cystinosis, with a much higher concentration in the western half of France, where more than $78 \%$ of the patients were found. The coastal areas, from north to south-west, gave a total of $53.2 \%$ of the cases.

The disease incidence was calculated after excluding: (1) children born before 1959, because diagnostic tests were not always reliable, and (2) children born after 1972, because the diagnosis was not made until an average age of 13 months \pm 10 months in our own series. 52 patients were born between 1959 and 1972. During this period, the number of affected children born each year was constant, 3 or 4 .

Because of the apparent heterogeneity of the 


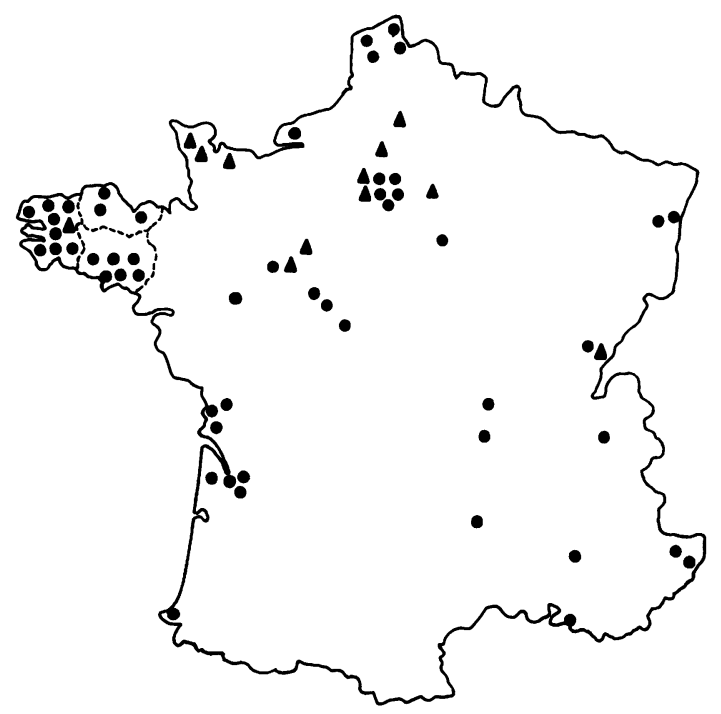

FIG. 1. Birthplaces of the patients with cystinosis: 1 born before 1959 and after $1972(n=12)$; born between 1959 and $1972(n=52)$.

geographical distribution of cystinosis, we have made two separate analyses (Table II): (1) France as a whole, except the three western 'departments' of Brittany (Finistère, Morbihan, Côtes-du-Nord), 35 cases ; (2) the three departments of Brittany, 17 cases, i.e. $32.7 \%$ of the sample. These departments represent only $3.7 \%$ of the total national births during the period 1959 to 1972 .

Thus, the incidence of cystinosis in western Brittany is 12.5 times that of the rest of France, and is of the magnitude of the estimate calculated by Bickel and Harris in Great Britain. If the incidence established in Brittany can be considered valid, one might wonder if there were no bias of ascertainment in the rest of France. Such a bias exists probably, but is not great: the geographical distribution of the replies to the questionnaires covers all university paediatric services in France. Cystinosis is a well-known disease, and its diagnosis is relatively easy. In addition, if the incidence of

TABLE II

COMPARISON BETWEEN BRITTANY AND REST OF FRANCE

\begin{tabular}{l|c|c}
\hline & $\begin{array}{c}\text { France except } \\
\text { Brittany }\end{array}$ & Brittany \\
\hline Patients & 35 & 17 \\
Live births 1959-1972 & 11425404 & 440458 \\
Disease incidence & $1 / 326440$ & $1 / 25909$ \\
Gene frequency & 0.0018 & 0.0062 \\
Frequency of heterozygotes & 0.0036 & 0.013 \\
\hline
\end{tabular}

the condition were the same in the rest of France as in Brittany, one should have found 441 cases of cystinosis instead of 35 . Such a bias is very unlikely.

On the other hand, as shown subsequently, application of Dahlberg's formula gives the result of gene frequency as being approximately similar to that found for the whole of France apart from Brittany.

\section{Consanguinity}

Among the 42 matings, for which data were available, which produced one or more affected children, $6(14.3 \%)$ were consanguineous. The coefficient of relationship between parents was $1 / 16$ for 3 families, $1 / 64$ for 2 , and $1 / 256$ for 1 family. This obviously high incidence of parental inbreeding was also observed by Bickel (16.7\%) and Paulin (10.8\%).

The mean coefficient of parental inbreeding for the 42 sibships was $530 \times 10^{-5}(\sigma=0.016)$, a figure 23 times that of the mean coefficient for marriages contracted in France, $23 \times 10^{-5}$, during the years 1956 to 1958 (Sutter and Goux, 1962). At present, the latter coefficient is probably much lower. In comparison, the mean coefficient of inbreeding in cystic fibrosis, the most common recessive disease in France $(1 / 2000)$, is $103 \times 10^{-5}$ (Feingold et al, 1974).

Brittany, the area of origin of a large proportion of the patients studied in our analysis, is a French region with a high consanguinity rate. However, among the 42 families studied, 31 are not from Brittany, and the 3 families, in which the parents are first cousins, belong to this sample. For this latter, the gene frequency was computed using Dahlberg's formula (Dahlberg, 1948). The frequency of first cousin marriages is $3 / 31$ in the nonBreton sample, and $2.1 \%$ in the general French population (Sutter and Goux, 1962). Thus, one obtains $\mathrm{q}=1.3 \times 10^{-3}$, which agrees with the gene frequency value computed above for France, excluding Brittany.

Another way of studying inbreeding in cystinosis was to compute the distance of parental birthplaces. For parents of patients and of control children, we have excluded non-married mothers and parents born outside France. The study thus concerns 53 pairs of control parents and 34 pairs of parents of patients. Fig. 2 shows the relative frequencies of different kinds of marriages according to the origin of the spouses with respect to the French administrative boundaries, the smallest territorial division being the 'commune', the largest, the province.

Except for parents born in the same territory, the percentage of parents born in the same administrative division is always higher for the parents of patients, when compared with parents of controls. 


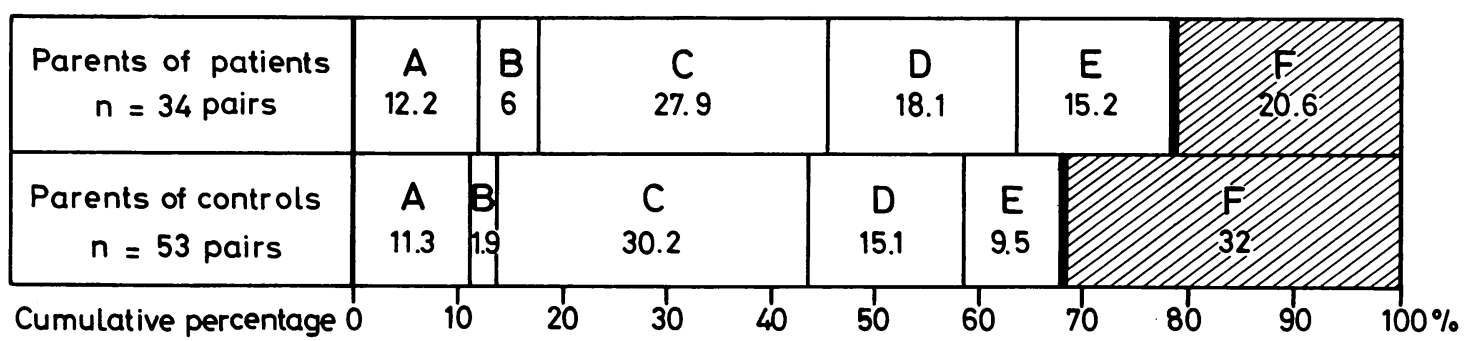

FIG. 2. Relative frequencies (\%) of different kinds of marriages according to the origin of the spouses. A: from the same 'commune' B: from different 'communes' of the same canton. C: from different cantons of the same territory. D: from different territories of the same 'department'. E: from different 'departments' of the same province. F: from different provinces.

The cumulative percentage shows that $79.41 \%$ of the parents of patients originated in the same province, as opposed to $68 \%$ for the controls. This $68 \%$ is in good agreement with the figure found by Girard (1974), $69 \%$ for the general French population. A detailed analysis shows that the increase in the overall percentage of patients' parents born in the same province is due largely to the Brittany families, where this percentage is $90.91 \%$.

Analysis of kilometric mean distance between parental birthplaces is summarized in Table III. This distance is always smaller for the parents of patients than for the parents of controls, and if the mean distance is approximately the same for all the controls, the distance for parents of patients is much smaller in Brittany than in the rest of France. In the case of one parental pair in the Breton sample, the distance was $543 \mathrm{~km}$. Excluding this case, the mean distance for the other 10 pairs decreases to $38.60 \mathrm{~km}$. Otherwise, the mean distance between parental birthplaces for the 5 known consanguineous pairs for which we have valid data, was $29.50 \mathrm{~km}$.

Demographic studies have shown that the distance between the location of the birthplaces of the spouses was negatively correlated with inbreeding and that a decrease in inbreeding was accompanied by

\section{TABLE III}

DISTANCES $(\mathrm{km})$ BETWEEN BIRTHPLACES OF PARENTS (standard deviation in parentheses)

\begin{tabular}{l|c|c|c|c}
\hline & \multicolumn{2}{|c|}{ Parents of Patients } & \multicolumn{2}{|c|}{ Parents of Controls } \\
\cline { 2 - 4 } & $\begin{array}{c}\text { No. } \\
\text { of } \\
\text { pairs }\end{array}$ & $\begin{array}{c}\text { Mean } \\
\text { distance } \\
(\mathrm{km})\end{array}$ & $\begin{array}{c}\text { No. } \\
\text { of } \\
\text { pairs }\end{array}$ & $\begin{array}{c}\text { Mean } \\
\text { distance } \\
(\mathrm{km})\end{array}$ \\
\hline Brittany & 11 & $\begin{array}{c}84.45 \\
(163.90)\end{array}$ & 19 & $\begin{array}{c}146 \\
(234.94)\end{array}$ \\
\hline France except Brittany & 23 & $\begin{array}{c}125.36 \\
(228.11)\end{array}$ & 34 & $\begin{array}{c}170.85 \\
(266.43)\end{array}$ \\
\hline France Total & 34 & $\begin{array}{c}111.73 \\
(209.06)\end{array}$ & 53 & $\begin{array}{c}165.54 \\
(260.04)\end{array}$ \\
\hline
\end{tabular}

an increase in the distance between the birthplaces of spouses (Sutter, 1958; Girard, 1974). The two methods used in the study show that the mean distance is generally smaller for the parents of patients with a rare recessive disease. Despite the small size of the sample, the data suggest that this study of parental distance may represent an indirect test of inbreeding, the reliability of which may be greater than interview information. For example, despite the fact that Brittany is a French area with a high consanguinity rate, the investigation did not enable us to single out proportionately greater numbers of cases of parental inbreeding among Breton patients than among patients from other parts of France. However, the kilometric study in Brittany shows that, both in the control group $(146 \mathrm{~km})$ and for the patients' group $(84 \mathrm{~km})$, these distances are smaller when compared with the remainder of France.

Nevertheless, further studies are needed to substantiate the validity of the two methods proposed above. Many authors have studied the birthplaces of parents and grandparents (Carter and Woolf, 1961). Morton et al (1973), in particular, has used the same methodology applied to the familial or isolated types of retinal degeneration in Switzerland, which suggests that 'the distance interval is a sensitive test for recessive inheritance, which is not vitiated by incomplete ascertainment of inbreeding'.

\section{Blood groups}

The analysis of two erythrocyte polymorphisms (ABO and $\mathrm{Rh}$ ) of 43 patients shows (Table IV) no significant differences for $\mathrm{Rh}$ and a large excess of group A among these patients when compared with overall French data (Moullec, 1964).

An analysis of distribution of blood groups in patients with cystinosis has not, to our knowledge, been done in any of the other studies of this disease. The findings are difficult to explain genetically. Specifically, there is no excess of the group A in the Brittany population. 
TABLE IV

DISTRIBUTION (\%) OF ABO AND Rh BLOOD GROUPS

\begin{tabular}{l|c|c|c|c|c|c}
\hline & $\mathrm{A}$ & $\mathrm{B}$ & $\mathrm{AB}$ & $\mathrm{O}$ & $\mathrm{Rh}+$ & $\mathrm{Rh}-$ \\
\hline $\begin{array}{l}\text { Index patients } \\
\text { no. =43 } \\
\begin{array}{c}\text { Fonch overall } \\
\text { population }\end{array}\end{array}$ & 65.0 & 0 & 2.5 & 32.5 & 82.1 & 17.9 \\
\hline
\end{tabular}

\section{Conclusions}

The concentration of a relatively high number of cases of cystinosis in western Brittany has no correlation with the density of the population in that area, which contributes only $3.7 \%$ to the total of French births. One may also say that it is not dependent on an ascertainment bias.

The genetic reason for this discrepancy is obscure. The relatively high frequency of cystinosis in Brittany cannot be the result of a greater degree of inbreeding only. There is no proof of any particular advantage for heterozygote status, especially in Brittany. One possible explanation for the findings is that the deleterious gene has been preserved at a high frequency level by faulty dilution in the mainstream of the general population.

This study provides further evidence that the geographical distribution of many genetic diseases is uneven. Some insight into the gene pools of populations can be obtained from the study of genetic diseases. Many studies are attempting to determine the contribution of hereditary pathology to defining populations (Lalouel, 1970; Ramot, 1973), and it is possible that these 'markers' will be shown to be more discriminant than the classical polymorphisms.

The authors are indebted to the 140 chiefs of services of paediatrics and to the 33 physicians of haemodialysis centres for their collaboration. They also acknowledge the help of Dr S. R. Berenberg (International Children's Centre) for the revision and helpful criticism in the preparation of the manuscript, and Y. Lachenal for secretarial assistance.

REFERENCES

Abderhalden, E. (1903). Familiäre Cystindiathese. Zeitschrift für physiologische Chemie, 38, 557-564.
Bickel, H. and Harris, H. (1952). The genetics of Lignac-Fanconi disease. Acta Paediatrica Uppsala, 42, Suppl. 90, 22-26.

Brubaker, R. F., Wong, V. G., Schulman, J. D., Seegmiller, J. E., and Kuwabara, T. (1970). Benign cystinosis. The clinical, biochemical and morphologic findings in a family with two affected siblings. American fournal of Medicine, 49, 546-550.

Carter, C. O. and Woolf, L. I. (1961). The birthplaces of parents and grandparents of a series of patients with phenylketonuria in Southeast England. Annals of Human Genetics, 25, 57-64.

Dahlberg, G. (1948). Mathematical Methods for Population Genetics. Karger, Basel.

Feingold, J., Hennequet, A., Jehanne, M., Feigelson, J., Toudic, L. Quiniou, O., and Briard, M. L. (1974). Fréquence de la fibrose kystique du pancréas en France. Annales de Génétique, 17, 257259.

Girard, A. (1974). Le Choix du Conjoint, 2nd ed. Presses Universitaires de France, Paris.

Goldman, H., Scriver, C. R., Aaron, K., Delvin, E., and Canlas, Z. (1971). Adolescent cystinosis: comparisons with infantile and adult forms. Pediatrics, 47, 970-988.

Kroll, W., Lichte, K. H., Lutz, P., and Maurer, R. (1973). Cystinosis: quantitative assay of cystine accumulation of homozygotes and heterozygotes. Humangenetik, 17, 337-340.

Kroll, W. and Lichte, K. H. (1973). Cystinosis: a review of the different forms and of recent advances. Humangenetik, 20, 75-87.

Lalouel, J. M. (1970). Concentrations locales d'affections héréditaires rares. Monograph. Annales de Génétique, pp. 190.

Lamy, M., Royer, P., Frezal, J., and Rey, J. (1968). Maladies Héréditaires du Métabolisme Chez l'Enfant. Masson, Paris.

Milunsky, A., Littlefield, J. W., Kanker, J. M., Kolodny, E. M., Shih, V. E., and Atkins, L. (1970). Prenatal genetic diagnosis. Nerv England fournal of Medicine, 283, 1370-1441.

Morton, N. E., Klein, D., Hussels, I. E., Dodinval, P., Todorov, A., Lew, R., and Yee, S. (1973). Genetic structure of Switzerland. American fournal of Human Genetics, 25, 347-361.

Moses, S. W. (1975). Cystinosis in Israël. Harefuah. 88, 122129.

Moses, S. W., Basman, N., Skibin, A., Biran, H., and Gutman, A. (1973). Genetic traits and diseases in the North African Jewish community. Israel fournal of Medical Sciences, 9, 1407-1409.

Moullec, J. (1964). Les Groupes Sanguins. Presses Universitaires de France, Paris.

Norio, R., Nevanlinna, H. R., and Perheentura, J. (1973). Hereditary diseases in Finland. Annals of Clinical Research, 5, 109-141.

Paulin, D. (1964). La cystinose. Revue de la littérature. Medical Dissertation, Paris.

Ramot, B. (ed.) (1973). Genetic polymorphysms and diseases in man. Proceedings of Sheeba International Symposium. Israel fournal of Medical Sciences, 9, 1129-1533.

Schneider, J. A. (1969). The early diagnosis of cystinosis. Fournal of Pediatrics, 74, 114-117.

Schulman, J. D. (1970). Heterozygote studies in cystinosis. Clinica chimica Acta, 29, 73-79.

Schulman, J. D. (ed.) (1973). Cystinosis. DHEW Publication, No. (NIH), 72-249. U.S. Government Print Office, Washington.

Schulman, J. D. (1974). Cystinosis. Birth Defects: Original Article Series, 4, 114-117.

Sutter, J. (1958). Evolution de la distance séparant le domicile des futurs époux. Population, 13, 226-235.

Sutter, J. and Goux, J. M. (1962). Evolution de la consanguinité en France de 1926 à 1958 . Population, 17, 683-702.

Williamson, D. A. J. (1952). Cystinosis. Archives of Disease in Childhood, 27, 356-363. 